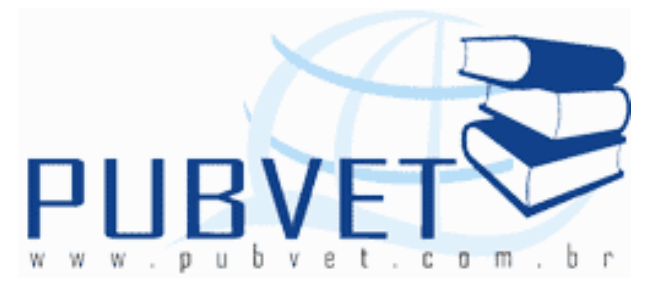

PUBVET, Publicações em Medicina Veterinária e Zootecnia.

\title{
Relato de caso de cirrose biliar em felino Felis domesticus
}

Humberto Eustáquio Coelho ${ }^{1}$, Tatiane Furtado de Carvalho ${ }^{2}$, Hélio Alberto $^{3}$, Carla Cunha Locce ${ }^{4}$, Karina Danielle Cobo Silva ${ }^{4}$, Claúdio Henrique Gonçalves Barbosa $^{1}$, Rodrigo Supranzetti de Rezende ${ }^{1}$, Flávia Maria Esteves Machado ${ }^{1}$

${ }^{1}$ Professor na Universidade de Uberaba,

${ }^{2}$ Residente de Patologia Animal na Universidade de Uberaba,

${ }^{3}$ Técnico do Laboratório de Anatomia Patológica do Hospital Veterinário de Uberaba (HVU).

${ }^{4}$ Acadêmico do curso de Medicina Veterinária da Universidade de Uberaba

\section{Resumo}

O presente trabalho relata um caso de cirrose biliar em um felino de três anos e meio, sem raça definida, na região de Uberaba-MG. O quadro clínico manifestado pelo animal foi apatia, desorientação, hiporexia e polidipsia, anúria, cegueira, mucosas hipocoradas com leve desidratação. Na necropsia os achados macroscópicos encontrados foram: hidroperitônio, hidrotórax, hidropericárdio, edema pulmonar, esôfago avermelhado, rins com nefrose colêmica e cirrose hepática. Achados microscópicos: cirrose biliar e glomérulonefrite. Cirrose biliar é uma apresentação da evolução de colangiohepatite. Por meio deste relato descrevemos os aspectos clínicos e patológicos desta patologia.

Palavras-chave: Fígado, Felis domesticus, insuficiência hepática. 
COELHO, H.E. et al. Relato de caso de cirrose biliar em felino Felis domesticus. PUBVET, Londrina, V. 5, N. 37, Ed. 184, Art. 1240, 2011.

\section{Case of biliary cirrhosis in feline Felis domesticus}

\section{Summary}

This paper reports a case of biliary cirrhosis in a cat for three years and a halfbreed in the region of Uberaba-MG. Clinical signs of the animal was apathy, disorientation, appetite loss, and polydipsia, anuria, blindness, pale mucous membranes with mild dehydration. At autopsy the macroscopic findings were: hydroperitoneum, hydrothorax, hydropericardium, pulmonary edema, reddish esophagus, kidneys, liver cirrhosis and nephrosis colema. Microscopic findings: biliary cirrhosis and glomerulonephritis. Biliary cirrhosis is an introduction to the evolution of hepatitis colangio. Through this report we describe the clinical and pathological features of this pathology.

Keywords: Liver, Felis domesticus, liver failure.

\section{INTRODUÇÃO}

O fígado é um órgão vital para o funcionamento do organismo e realiza inúmeras funções essenciais. Doenças hepáticas são muito comuns em cães e gatos. Uma hepatopatia é caracterizada por qualquer distúrbio que acarrete uma lesão de hepatócitos, colestase ou ambas e pode ser a causa ou não de uma insuficiência hepática. A insuficiência hepática ocorre quando cerca de setenta a oitenta por cento da massa funcional hepática estiver comprometida. As causas destes distúrbios podem ser diversas, tais como intoxicação por agentes químicos ou drogas, doenças neoplásicas, metabólicas, isquêmicas e infecciosas (MORIN, 2008).

Algumas das causas de insuficiência hepática em cães e gatos são: desvio portacaval congênito, hepatite crônica ativa, necrose hepática aguda, lipidose hepática felina, hepatite associada ao cobre, cirrose, tumores hepáticos e infecções bacterianas e virais (FENNER, 2003).

As principais manifestações clínicas da insuficiência hepática são encefalopatias hepática, icterícia e ascite (MORIN, 2008). 
COELHO, H.E. et al. Relato de caso de cirrose biliar em felino Felis domesticus. PUBVET, Londrina, V. 5, N. 37, Ed. 184, Art. 1240, 2011.

O animal pode, ainda, apresentar prejuízo do metabolismo, com crescimento retardado, letargia e perda de peso. A deficiência de fatores de coagulação pode resultar em coagulopatias (FENNER, 2003). Infecções, especialmente nos sistemas respiratório e urinário, também podem ocorrer nos pacientes. Muitos também desenvolvem insuficiência renal (FIGUEIREDO, 2009). Ascite pode se instalar, devido ao aumento da resistência vascular ao fluxo de sangue portal. E a administração de drogas em pacientes hepáticos deve ser muito cautelosa, visto que boa parte delas é biotransformada no fígado, o que torna seu metabolismo imprevisível em caso de insuficiência (FENNER, 2003).

A insuficiência hepática é uma disfunção que resulta em deterioração da função hepática. Pode ser classificada como aguda ou crônica (FENNER, 2003). Quando acompanhada por encefalopatia, passa a ser denominada insuficiência hepática fulminante, uma condição bastante grave, mas potencialmente reversível (FIGUEIREDO, 2009; TREY; DAVIDSON, 1970).

A terminologia empregada na classificação das doenças inflamatórias do fígado de gatos é confusa. Atualmente não há uma classificação de aceitação universal para as doenças inflamatórias do fígado de felinos (WEISS et al., 2001). Três formas dessa síndrome têm sido reconhecidas com base no aspecto histológico das lesões hepáticas que presumivelmente refletem as diversas fases da evolução clínica da enfermidade e o caráter progressivo da lesão hepática. Essas incluem a colangite/colangio-hepatite supurativa, a colangite/colangio-hepatite não supurativa crônica progressiva e a cirrose biliar ou colangite esclerosante (EDWARDS et al., 1983, NAKAYAMA et al., 1992, DAY, 1995).

Complexo colangite/ colangio-hepatite $(\mathrm{CC} / \mathrm{CH})$ é a inflamação dos ductos biliares e do parênquima hepático circunjacente, sendo causa mais freqüente de doenças hepáticas em felinos. Estágio terminal dessa entidade associada à inflamação crônica hepatobiliar que resulta em fibrose portal e hiperplasia ductal, as lesões que correspondendo a cirrose biliar ou colangite 
COELHO, H.E. et al. Relato de caso de cirrose biliar em felino Felis domesticus. PUBVET, Londrina, V. 5, N. 37, Ed. 184, Art. 1240, 2011.

esclerosante, uma das formas de apresentação do complexo colangite (ILHA et al, 2004).

Colangite/colangio-hepatite não-supurativa e cirrose biliar corresponderiam a estágios evolutivos subseqüentes da síndrome, quando o agente infeccioso já teria sido destruído, mas mecanismos imunológicos perpetuariam a agressão ao sistema hepatobiliar. Colelitíase, trematódeos, protozoários e doença renal (síndrome nefrótica) também têm sido associadas ao CC/CH (DAY, 1995). Lesões inflamatórias no pâncreas e intestinos podem ocorrer simultaneamente àquelas observadas no fígado (WEISS et al., 1996). O quadro clínico observado nos animais afetados é consistente com insuficiência hepática e consiste em icterícia, caquexia, fígado firme e de aspecto nodular e ascite (ILHAS, et al. ,2004).

A cirrose caracteriza-se por fibrose difusa e substituição de tecido hepático por nódulos regenerativos estruturalmente anormais. A cirrose é o estágio final irreversível da lesão hepática crônica causada por infecção, hepatotoxinas (cobre e anticonvulsivos), lesão imunológica (hepatite crônica), colestase crônica (colângio-hepatite crônica nos gatos) e hipoxia. A morte hepatocítica, leva a um reparo através de fibrose e de regeneração nodular. Esses processos comprometem posteriormente os hepatócitos normais adjacentes, o fluxo sanguíneo intra-hepático e o fluxo biliar intra-hepático; consequentemente, a cirrose atinge um ponto que se torna autoperpetuante (BIRCHARD; SHERDING, 1998). Trata-se da forma menos comum dessa síndrome. O número reduzido de relatos de casos de cirrose biliar tem sido atribuído ao fato de que a maior parte dos animais afetados pela $\mathrm{CC} / \mathrm{CH}$ morre espontaneamente ou é submetido à eutanasia antes de a doença progredir para a sua fase terminal (DAY, 1995).

A cirrose biliar é morfologicamente semelhante à colangite esclerosante e à cirrose biliar primária dos humanos (GAGNE et al., 1996). Etiologias infecciosas e processos imunomediados têm sido apontados como alguns dos fatores envolvidos na patogenia desse complexo de enfermidades hepáticas inflamatórias que acometem os felinos. Infecção bacteriana ascendente tem 
COELHO, H.E. et al. Relato de caso de cirrose biliar em felino Felis domesticus. PUBVET, Londrina, V. 5, N. 37, Ed. 184, Art. 1240, 2011.

sido sugerida como uma das causas dessa síndrome. Microrganismos pertencentes à flora comensal do trato gastrintestinal seriam capazes de invadir a árvore biliar e atingiriam o sistema hepatobiliar provocando inflamação peribiliar e fibrose hepática induzida por citocinas (DAY, 1995; CULLEN \& CHAPMAN, 2001). Em humanos, há fortes evidências epidemiológicas da associação entre a colangite esclerosante primária e as doenças inflamatórias intestinais (VIERLING, 2001). Essa hipótese também tem sido levantada para o CC/CH dos felinos (WEISS et al., 1996; LAPOINTE et al., 2000; WEISS et al., 2001).

A cirrose biliar segue-se à colangite crônica, que pode ser decorrente da obstrução em algum ponto no sistema dutal extra-hepático, ou da obstrução de ductos biliares intra-hepáticos. Com freqüência a cirrose biliar é complicada por infecção bacteriana da árvore biliar. Inicialmente com uma obstrução extra-hepática, os ductos biliares ficam dilatados e ocorre proliferação de dúctulos. Esse quadro é seguido por fibrose, que a princípio se concentra em torno dos ductos biliares, porém mais tarde estende-se até os lóbulos hepáticos. Os ductulos biliares recém-formados (reação celular ductular) podem ser conspícuos, e habitualmente ocorre uma infiltração de células inflamatórias que podem ser principalmente neutrófilos, caso haja uma infecção bacteriana secundária. O que é chamado de cirrose biliar primária (colangite esclerosante primária) resulta de um processo destrutivo de ductos biliares intra-hepáticos, inicialmente caracterizado pela necrose do epitélio dutal e por um infiltrado inflamatório mononuclear. O número de grandes ductos das tríades diminui, ocorrendo uma proliferação associada de pequenos dúctulos. Os ductos biliares ficam circundados por tecido conjuntivo fibroso, que acaba por estender-se desde as tríades. Especula-se que certos mecanismos imunes sejam os eventos causadores (JONES et al., 2000).

No exame físico e na anamnese do animal, alguns aspectos devem ser especialmente investigados. Um deles é a exposição prévia a drogas hepatotóxicas: gatos, por exemplo, podem desenvolver insuficiência hepática após exposição ao paracetamol. As características das fezes e da urina devem 
COELHO, H.E. et al. Relato de caso de cirrose biliar em felino Felis domesticus. PUBVET, Londrina, V. 5, N. 37, Ed. 184, Art. 1240, 2011.

ser consideradas, para que se avalie a presença de sangramento gastrointestinal e bilirrubinúria. Idade, sexo e raça do animal podem ajudar a direcionar a suspeita para uma determinada doença hepática. O exame das mucosas é essencial, pois permite visualizar uma possível icterícia. E o exame neurológico deve ser realizado, para verificar se a encefalopatia hepática já se instalou (FENNER, 2003).

Alguns exames complementares a ser realizados em caso de suspeita de doença hepática são: perfil hepático (com avaliação, no mínimo, de transaminase, fosfatase alcalina, bilirrubina, glicose, proteína total e albumina), urinálise (para detectar bilirrubinúria), tempo de coagulação ativada ou perfil de coagulação (para avaliar o risco de sangramento) e radiografias abdominais (determinando tamanho e forma do fígado) (FENNER, 2003).

A terapia a ser usada para os pacientes afetados pelo $\mathrm{CC} / \mathrm{CH}$ é determinada de acordo com o estádio da doença, que é determinado com base no exame histológico do fígado. O prognóstico dessa entidade é reservado em função de a condição usualmente ser refratária aos tratamentos empregados (DAY, 1995). Diversos estudos abordando os aspectos clínico-patológicos, radiográficos e ultrassonográficos do complexo colangite/colangio-hepatite felina têm sido realizados (GAGNE et al., 1996; WEISS et al., 1996; GAGNE et al., 1999). No Brasil, no entanto, os estudos a respeito dessa enfermidade são escassos e limitam-se a relatos esporádicos sobre procedimentos diagnósticos e tratamento de casos isolados da doença em seus estádios iniciais (PANTIN et al., 1993; MOURA et al., 1996). A escassez de recursos diagnósticos nos estabelecimentos veterinários, os recursos financeiros limitados dos clientes e a resistência oferecida pelos proprietários de animais de guarda e companhia no que se refere ao esclarecimento da causa da doença de seus animais através de exames laboratoriais complementares dificultam os estudos a respeito da prevalência dessa condição nas populações felinas locais nas diversas regiões do Brasil (ILHAS, et al. ,2004). 
COELHO, H.E. et al. Relato de caso de cirrose biliar em felino Felis domesticus. PUBVET, Londrina, V. 5, N. 37, Ed. 184, Art. 1240, 2011.

O presente relato de caso tem como objetivo compartilhar informações através da descrição das características clínica e patológicas observadas em um felino com cirrose biliar, já que são poucos os casos relatados sobre esta patologia.

\section{RELATO DE CASO}

Um gato (Felis domesticus), 3 anos de idade, sem raça definida, $3 \mathrm{Kg}$ (Figura 01), foi encaminhado ao Hospital Veterinário de Uberaba/ MG, pois segundo o proprietário o animal possuía um histórico de síndrome urológica felina e no momento, apresentou-se apático, prostado, hiporexia, anúria, com alterações neurológicas representadas por desorientação e cegueira.

Durante a consulta o animal apresentava-se em estação, estado nutricional regular, mucosas hipocoradas, desidratação moderada, temperatura de $38^{\circ} \mathrm{C}$, freqüência cardíaca de $100 \mathrm{bpm}$ e respiratória de $20 \mathrm{mpm}$. À palpação constatou-se sensibilidade dolorosa na bexiga, esplenomegalia, Observou-se também presença de halitose urêmica.

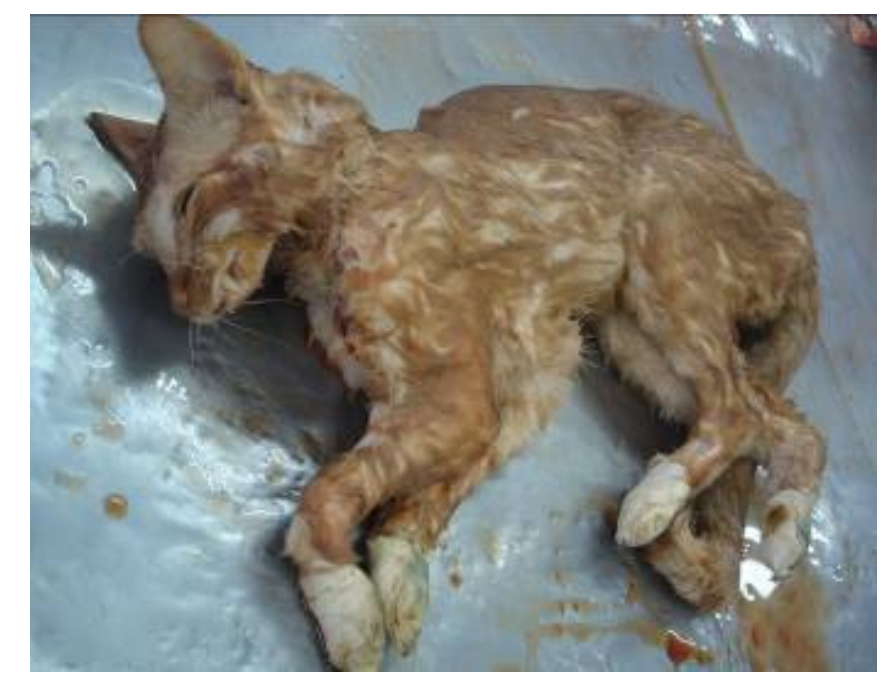

Figura 01. Gato, 3 anos de idade, sem raça definida e pesando $3 \mathrm{Kg}$. 
COELHO, H.E. et al. Relato de caso de cirrose biliar em felino Felis domesticus. PUBVET, Londrina, V. 5, N. 37, Ed. 184, Art. 1240, 2011.

Foram solicitados os exames complementares: hemograma completo, hemogasometria e bioquímicas séricas (uréia, creatinina, ALT, fosfatase alcalina, glicose e colesterol total).

As alterações observadas no hemograma foram anemia macrocítica normocrômia, presença de metarrubrícitos, intensa anisocitose e policromasia, trombocitopenia, leucocitose, linfocitose e moderados linfócitos reativos. Nos exames bioquímicos a ALT, a glicose e o colesterol apresentaram-se aumentados. Na hemogasometria observou-se aumento de sódio, redução do potássio, da pressão parcial de dióxido de carbono, da concentração de bicarbonato de sódio e BE.

O animal veio a óbito e então realizou-se a necropsia no Laboratório de Patologia Animal. Os achados macroscópicos consistiam da presença de aumento da quantidade de líquido de coloração citrina nas cavidades abdominal e torácica, respectivamente, hidroperitoneo e hidrotórax; esôfago avermelhado, edema pulmonar, hidropericárdio, esplenomegalia congestiva, presença de coágulo cruórico no ventrículo esquerdo, endocardiose com nódulos na valva bicúspide, os rins estavam com seu volume aumentado, amarelados e pálidos indicando nefrose colêmica e pâncreas pálido. O fígado estava firme e com a superfície natural e de corte irregulares e de aspecto reticulado conferido por linhas esbranquiçadas, espessas, que se entrecruzavam no parênquima hepático e se alternavam com áreas amareladas. Os ductos biliares intra-hepáticos mais calibrosos estavam mais evidentes, ectásicos e esverdeados devido a retenção de bile (colestase). com manchas brancacentas e amareladas caracterizando uma cirrose hepática (Figura 02). 
COELHO, H.E. et al. Relato de caso de cirrose biliar em felino Felis domesticus. PUBVET, Londrina, V. 5, N. 37, Ed. 184, Art. 1240, 2011.

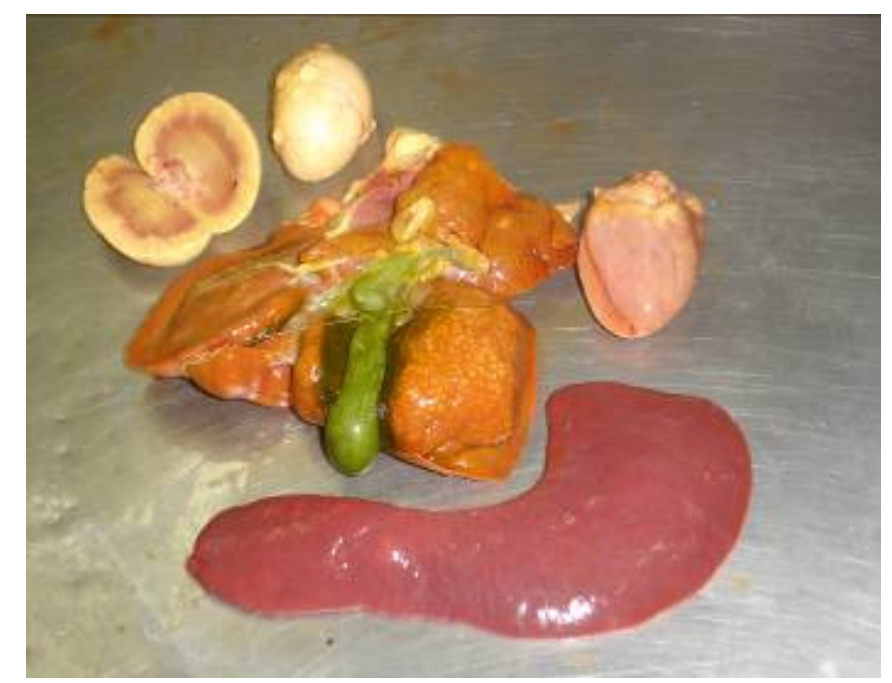

Figura 02. Órgãos de um felino com cirrose biliar, evidenciando as alterações macroscópicas, nefrose colêmica, cirrose biliar e esplenomegalia congestiva.

No exame histopatológico do fígado e rins os achados microscópicos foram cirrose biliar e glomerulonefrite. Histologicamente, havia fibrose periportal, severa, dissecante, em ponte, com a formação de pseudolóbulos, associada a infiltrados inflamatórios linfoplasmocitários, proliferação e distensão acentuadas dos ductos biliares periportais, dilatação de vasos linfáticos dos espaços-porta, retenção biliar (colestase) hepatocelular, canalicular e ductal e acúmulo de células mononucleares, restos celulares, fibrina e bile na luz dos ductos biliares.

\section{DISCUSSÃO}

Pelo fato da cirrose biliar se tratar uma evolução da $\mathrm{CC} / \mathrm{CH}$ a maioria dos animais tem morte espontânea ou são submetidos a eutanásia antes de manifestá-la, sendo por este motivo raramente observada nos felinos (ILHA et al., 2004). 
COELHO, H.E. et al. Relato de caso de cirrose biliar em felino Felis domesticus. PUBVET, Londrina, V. 5, N. 37, Ed. 184, Art. 1240, 2011.

O animal apresentou sinais clínicos de desorientação e amaurose (cegueira de origem no sistema nervoso central), associados aos achados histopatológicos de cirrose biliar, assim podemos caracterizar um quadro de encefalopatia hepática (EH). É um distúrbio reversível da função neuronal associada com a exposição do sistema nervoso central a substâncias neurotóxicas devido a uma doença hepatocelular primária ou com desvio da circulação portal do fígado (BRUNCH, 1991). A EH esta relacionada com um shunt portosistêmico adquirido, assim também como uma enfermidade hepática grave. A capacidade detoxificadora e de síntese do fígado estarão reduzidas. O amoníaco e outros metabólitos das proteínas entéricas penetram diretamente na circulação geral e cerebral, onde alteram o metabolismo encefálico produzindo falsos neurotransmissores e também, possíveis dano neural (CENTER, 2005).

As manifestações neurológicas mais comuns são a diminuição da atividade mental e a responsividade que variam desde depressão discreta até coma. Outros sintomas incluem dementia, convulsões, letargia, alterações de comportamento (agressividade ou histeria), incoordenação locomotora, anorexia, êmese, diarréia e hipersalivação, principalmente em gatos (BUNCH, 1991).

Clinicamente observou-se ascite, perda de peso, desidratação e halitose urêmica, o que esta de acordo com Tilley et al. (2003) que relatam além desses outros sinais clínicos de hepatopatias como anorexia, letargia, opacidade da córnea, vômito, diarréia, poliúria ou polidipsia, ascite e icterícia.

Icterícia, vômitos, dor abdominal e emagrecimento progressivo são sinais clínicos consistentes com doença hepática difusa (insuficiência hepática) em gatos e foram observadas nos três casos de cirrose biliar descritos no presente estudo. O quadro clínico manifestado pelos animais em casos de cirrose biliar não é específico e pode ocorrer em diversas doenças de felinos que provocam icterícia pré-hepática, hepática ou pós-hepática e caquexia. Essas incluem: (a) o parasitismo por Mycoplasma haemofelis (Haemobartonella felis) (GREENE, 1998), (b) a infecção por Cytauxzoon felis simile (GREENE, 1998, 
COELHO, H.E. et al. Relato de caso de cirrose biliar em felino Felis domesticus. PUBVET, Londrina, V. 5, N. 37, Ed. 184, Art. 1240, 2011.

SCOFIELD et al., 2002), (c) a anemia hemolítica auto-imune (FIGHERA et al., 2001), (d) a lipidose hepática idiopática (ZAWIE \& GARVEY, 1984), (e) o diabete melito (ZAWIE \& GARVEY, 1984) (f) o parasitismo por Platynosomum fastosum (GREENE, 1998), (g) a infecção pelo vírus da peritonite infecciosa felina (PIF) (GREENE, 1998), (h) as neoplasias hepatobiliares primárias tais como colangiocarcinoma, carcinoma hepatocelular e linfossarcoma e os tumores metastáticos ou multicêntricos (ZAWIE \& GARVEY, 1984), (i) a cirrose hepática de etiologia multifatorial (ZAWIE \& GARVEY, 1984), (j) a colelitíase (ZAWIE \& GARVEY, 1984) e (k) as doenças associadas à infecção pelo vírus da leucemia felina (FeLV) e vírus da imunodeficiência felina (FIV) p.ex. linfossarcoma multicêntrico (GREENE, 1998).

$\mathrm{Na}$ necropsia pode-se encontrar edema e esplenomegalia congestiva. A ascite pode resultar de hipertensão portal sozinha ou da combinação do aumento da pressão sanguínea portal e redução da pressão oncótica devido à hipoproteinemia (DUNN, 2001). A esplenomegalia congestiva é devido à hipertensão portal causada pela cirrose biliar, com o aumento da pressão sanguínea dentro do sistema porta hepático aumentando a pressão na veia esplênica, fazendo com que o baço "inche".

No hemograma observou-se uma anemia macrocítica normocrômica, com resposta medular regenerativa, pela presença de policromasia e anisocitose. De acordo com Nelson et al. (2006), no hemograma completo, há poucas alterações nas células sanguíneas que sugerem doença hepatobiliar.

Nas bioquímicas séricas notou-se aumento da ALT, da glicose e colesterol. A ALT é uma enzima de extravasamento que está livre no citoplasma dos hepatócitos, esta enzima é essencialmente hepatoespecífica para cães e gatos. O aumento da atividade sérica dessa enzima indica uma lesão celular liberando-a para a circulação. Pequenos aumentos da sua atividade não

têm relevância, pois o grau da lesão hepática é responsável pelo aumento da atividade da ALT. Entre os testes de função hepática é considerado o mais comum e o melhor para detecção da lesão hepática (THRALL, 2007). 
COELHO, H.E. et al. Relato de caso de cirrose biliar em felino Felis domesticus. PUBVET, Londrina, V. 5, N. 37, Ed. 184, Art. 1240, 2011.

A excreção do colesterol é feita pela bile, portanto um distúrbio no fluxo biliar (colestase) pode aumentar o seu nível no sangue ocorrendo hipercolesterolêmica. O fígado é o principal órgão de síntese de colesterol, em alguns tipos de insuficiência hepática pode ocorrer à diminuição no sangue (hipocolesterolemia) (THRALL, 2007).

O fígado tem participação importante no metabolismo de glicose sendo ela absorvida no intestino delgado e é transportada através do sistema porta chegando aos hepatócitos que transformam glicose em glicogênio mantendo assim o seu nível ideal no sangue. Em animais com insuficiência hepática a glicemia pode estar baixa ou alta isso tem relação devido à menor atividade da glicogenólise nos hepatócitos resultando na sua diminuição. O aumento da glicose pode ocorrer quando tiver menor absorção hepática resultando em hiperglicemia pós-prandial prolongada (COLES, 1994; TRALL, 2007).

A alteração histopatológica típica da cirrose biliar é a colangite crônica não supurativa e destrutiva, que envolve os ductos biliares interlobulares de 40-80 $\mu \mathrm{m}$ de diâmetro associada à presença de infiltrado inflamatório portal com redução de ductos biliares (KUMAGI e HEATHCOTE, 2008). São quatro estágios histológicos que caracterizam: inflamação restrita às tríades portais (ADDISON e GULL, 1851); inflamação que se estende além dos tratos portais para o parênquima intralobular, com redução numérica dos ductos biliares normais (KUMAGI e HEATHCOTE, 2008); septos fibrosos ligando tratos portais adjacentes; e cirrose (LLEO, 2008).

\section{REFERÊNCIAS}

ADDISON T. GULL W.: On a curtain affection of the skin-vetiligoidea-<-plana-tuberosa. Guys Hosp Rept. 1851; 7: G265-277.

BICHARD, S.J.; SHERDING, R.G. Manual Saunders - Clínica de Pequenos Animais. 2.ed. São Paulo: Roca, 2003.

CENTER. S. A. Feline Hepatic Lipidosis. Veterinary Clinics Small Animal Practice. 35 (2005) 225-269.

COELHO, H.E. Patologia Veterinária. São Paulo: Manole, 2002. 
COLES, E.H. Patologia Clínica Veterinária. 3 ed. São Paulo: Manole p.185-219, 1994.

CULLEN, S.; CHAPMAN R. Aetiopathogenesis of primary sclerosing cholangitis. Best Pract Res Clin Gastroenterol, v.15, n.4, p.577-589, 2001.

DAY, D.G. Feline cholangiohepatitis complex. Vet. Clin. North Am: Small Anim Pract, v.25, n.2, p.375-385, 1995.

EDWARDS, D.F.; McCRAKEN, M.D.; RICHARDSON, D.C. Sclerosing cholangitis in a cat. J Am Vet Med Assoc, v.182, n.7, p.710-712, 1983.

FENNER, W.R. Consulta rápida em clínica veterinária. Rio de Janeiro, Editora Guanabara Koogan, p269-273.

FIGHERA, R.A. et al. Anemia hemolítica auto-imune em gatos. In: ENCONTRO NACIONAL DE PATOLOGIA VETERINÁRIA (ENAPAVE), 10., 2001, Pirassununga, SP. Resumos... Jaboticabal: Funep, 2001. p.50.

FIGUEIREDO, F.A.F. 2009 [Online]. Insuficiência hepática fulminante. Homepage:http://www.medcenter.com/Medscape/content.aspx?LangType=1046\&menu_id=49 \&id $=1543$

GAGNE, J.M., WEISS, D.J.; ARMSTRONG, P.J.;LUND E.M.;FEENEY D.A.; KING V.L. Clinical features of inflammatory liver disease in cats: 41 cases (1983-1993). J Am Vet Med Assoc, v. 214, n. 4, p. 513-516, 1999.

GAGNE, J.M.; WEISS, D.J.; ARMSTRONG, P.J. Histopathologic evaluation of feline liver disease. Vet Pathol, v.33, p.521-526, 1996.

GREENE, C.E. Infectious diseases of dog and cat. 2.ed. Philadelphia : Saunders, 1998. 934p.

ILHA, M.R.S.; LORETTI, A.P.; BARROS, C.S.L. Cirrose biliar em felinos associada à ectasia do ducto cístico e desvios portossistêmicos extra-hepáticos. Ciência Rural, v. 34, n.4, p.11471153, 2004.

JONES, T.C.; HUNT, R.D.; KING, N.W. Patologia veterinária. 6a ed. São Paulo: Manole, 2000.

KUMAGI T, ONJI M. Presentation and diagnosis of primary biliary cirrhosis in the 21st. century. Clin Liver Dis. 2008; 12: 243-259.

LAPOINTE, J.M. et al. Enterococcus hirae enteropathy with cholangitis and pancreatitis in a kitten. Vet Pathol, v.37, p.282-284, 2000.

LLEO A, INVERNIZZI P, MACKAY IR, PRINCE H, ZHONG RQ, GERSHWIN ME. Etiopathogenesis of primary biliary cirrhosis. World J Gastroenterol. 2008; 14: 3328-3337.

MORIM, D.F. Hepatopatias e Insuficiência Hepática, revisão bibliográfica [monografia]. Rio de Janeiro: Instituto Qualittas de Pós graduação; 2008.

MOURA, L.R.C. et al. Colangite/colangio-hepatite supurativa felina. In: CONGRESSO BRASILEIRO DE CLÍNICOS VETERINÁRIOS DE PEQUENOS ANIMAIS, 18., 1996, Recife, PE. Anais. Recife : ANCLIVEPA, 1996. p.162. 
NAKAYAMA, et al. Three cases of feline sclerosing lymphocytic cholangitis. J Vet Med Sci, v.54, n.4, p.769-771, 1992.

NELSON, R. W.; COUTO, C.G. Testes Diagnósticos para o Sistema Hepatobiliar. Medicina Interna de Pequenos Animais. $3^{a}$ ed. Rio de Janeiro: Guanabara Koogan. pag.467-488, 2006.

PANTIN, M.A.; HAGIWARA, M.K.; CARVALHO, C.F. Diagnóstico e tratamento de colangio hepatite em um gato. In: CONGRESSO BRASILEIRO DA ANCLIVEPA, 15., 1993, Rio de Janeiro, RJ. Anais... Rio de Janeiro : ANCLIVEPA- RJ, 1993. p.50.

SCOFIELD, A. et al. Tipos morfológicos intra-eritrocitários de Cytauxzoon felis simile em gatos domésticos do Brasil. In: CONGRESSO BRASILEIRO DE MEDICINA VETERINÁRIA (CONBRAVET), 29., 2002, Gramado, RS. Anais... Porto Alegre : SOVERGS, 2002. p.1356.

THRALL, M. Hematologia e Bioquímica Clínica Veterinária 1 ed. Roca: São Paulo, p. 335354, 2007.

TREY, C.; DAVIDSON, L. S. 1970. The management of fulminant hepatic failure. In: Popper, H.; Schaffner, F. (eds): Progress in liver disease. New York, Grune and Stratton. p. 282298.

VIERLING, M. Animal models for primary sclerosing cholangitis. Best Pract Res Clin Gastroenterol, v.15, n.4, p.591-610, 2001.

WEISS, D.J.; GAGNE, J.M.; ARMSTRONG, P.J. Inflammatory liver disease in cats. Compend Contin Educ Pract Vet, v.23, n.4, p.364-373, 2001.

ZAWIE, D.A.; GARVEY, M.S. Feline hepatic disease. Vet Clin North Am: Small Anim Pract, v.2, p.1201-1230, 1984. 